\section{ESTUDO COMPARATIVO DA DIGESTIBILIDADE APARENTE DA MATÉRIA SECA DO CAPIM NAPIER (PENNISETUM PURPUREUM SCHUM) EM BOVINOS EUROPEUS (BOS TAURUS) E INDIANOS (BOS INDICUS)}

\author{
JOSÉ CARLOS MACHADO NOGUEIRA FILHO \\ Professor Assistente \\ Faculdade de Medicina Veterinária \\ e Zootecnia da USP
}

JOÃO SILVA MARCONDES VEIGA Professor Assistente Doutor

Faculdade de Medicina Veterinária

e Zootecnia da USP

MARIA ELY MISEROCHI DE OLIVEIRA
Professora Assistente Doutora

URIEL FRANCO ROCHA Professor Titular Instituto de Ciências Biomédicas da USP

MARIA CECILIA MARCONDES VEIGA Médica Veterinária

NOGUEIRA FILHO, J.C.M.; VEIGA, J.S.M.; OLIVEIRA, M.E.M.; ROCHA, U.F.; VEIGA, M.C.M. Estudo comparativo da digestibilidade aparente da matéria seca do capim Napier (Pennisetum purpureum Schum) em bovinos europeus (Bos taurus) $e$ indianos (Bos indicus). Rev.Fac.Med.vet.Zootec.Univ.S.Paulo, 19(1): 97-100, 1982.

RESUMO: Utilizando os métodos de colheita total e indicador $\left(\mathrm{Cr}_{2}\right.$ $\mathrm{O}_{3}$ ), para medir, respectivamente, a ingestāo e estimar a excreçāo de matéria seca, foram estudados os coeficientes de digestibilidade aparente da matéria seca do capim Napier (Pennisetum purpureum Schum), em cinco Bos taurus e cinco Bos indicus, fêmeas de 18 a 24 meses. Os resultados médios de dez dias de colheita de amostras revelaram que os de origem indiana possuiam capacidade de melhor digerir a forragem $(C D=46,41 \pm 1,28 \%$ ), que os componentes do grupo formado por taurinos ( $C D=42,41 \pm 0,85 \%)$. Estas diferenças apresentaram significância estatística ao nivel de 0,05 . A comparação com dados constantes na liteíatura mostrou que, relativamente à características aqui estudada, os Nelores brasileiros tiveram comportamento semelhante ao das demais raças de zebuinos existentes em outros países, quando cotejados com bovinos europeus.

UNITERMOS: Alimentos, digestibilidade*; Bovinos, raças* ; Bos taurus; Bos indicus.

\section{INTRODUÇÃO E LITERATURA}

Os zebuinos possuem maior capacidade de digerir alimentos volumosos que os taurinos. Isto tem sido demonstrado em diferentes países, nos quais a criaçăo de raças indianas se reveste de importância econômica (HUNGATE e $\mathrm{cols}^{5}$ ). Assim, mestiços Red Sindhi X Holandês provenientes das Filipinas revelaram maior capacidade de digestibilidade para forragens dali oriundas que animais da raça $\mathrm{Ho-}$ landesas dos Estados Unidos da América do Norte (GRANT e cols ${ }^{4}$ ).

No Brasil, onde prepondera a raça Nelore, poucas comparaçōes existem entre estes zebuinos e seus mestiços, de um lado e, europeus, de outro, seja quanto à capacidade de digerir forrageiras aqui existentes, seja quanto às consequências da utilização desses animais como doadores de "inóculum" para provas de digestibilidade "in vitro".

Diferenças nesse sentido tinham sido vislumbradas, há 20 anos, por ANDREASI e cols 1 , ao afirmarem que estudos planejados a fim de se determinarem quais as repercurssరes fisiológicas advindas das diferenças anatômicas, trariam à luz elementos importantes sobre as necessidades nutritivas específicas em Zebú.

Numerosos estudos são aproveitáveis para estabelecer comparaçōes entre a produtividade das diferentes raças e diferentes niveis de "sangue europeu" nas regiōes tropicais, mas poucos desses trabalhos tem sido planejados especificamente para esclarecer eventuais divergências de comportamento, entre eles ( $\operatorname{RENDEL}^{7}$ ).

O presente estudo objetiva comparar a capacidade de aproveitamento de forragens grosseiras por animais tipicamente europeus e zebú da raça Nelore.

\section{MATERIAL E MÉTODOS}

Foram utilizadas 10 fêmeas bovinas, com idades variando de 18 a 24 meses, sendo 5 produtos de cruzamento Dinamarques X Flamengo (lote I) e 5 da raça Nelore (lote II), todas pertencentes ao Centro Intraunidade de Zootecnia e Indústrias Pecuárias "Fernando Costa", em Pirassu. nunga, Estado de São Paulo, em cujas instalaçōes a parte experimental foi desenvolvida.

Os animais foram alojados em baias individuais e alimentados "ad libitum" com capim Napier (Pennisetum purpureum Schum), com mais de 180 dias de crescimento, recém cortado de capineira próxima.

$\mathrm{O}$ alimento, ofe recido em cochos, foi previamente pesado. Nestas oportunidades foram colhidas amostras do capim, bem como das sobras, as quais por sua vez também foram pesadas.

A cada animal foi administrado, duas vezes ao dia, às 6 e às 18 horas, cápsula de gelatina contendo $4 \mathrm{~g}$ óxido crômico, perfazendo a dose de $8,0 \mathrm{~g}$ diárias.

Os animais permaneceram sujeitos a este tratamento 
durante 15 dias, 5 considerados como fase préexperimental e mais 10 para a colheita das amostras.

As colheitas de fezes foram realizadas diretamente do solo impermeabilizado precedidas de rigorosa homogeneização dos excretas.

As amostras referentes às excreçð̄es individuais diárias (de 24 horas), bem como às de capim oferecido e respectivas sobras, foram acondicionadas em vidros e armazenadas a $5^{\circ} \mathrm{C}$, para posterior análise.

As determinaçōes da matéria seca foram procedidas segundo o método preconizado pela A.O.A.C. 2 e as de óxido crômico obedeceram ao proposto por SCHURCH e cols 8 .

As fezes eliminadas em periodos de 24 horas foram estimadas pela fórmula de SMITH \& REID $^{9}$.
Os coeficientes de digestibilidade foram transformados em ângulos (ang $=\operatorname{arcsen} \sqrt{ } \%$ ) entes de serem submetidos às análises de variância, segundo SNEDECOR \& COCHRAN 10 , e adotado o nível crítico de 0,05 de probabilidade.

\section{RESULTADOS}

Os coeficientes de digestibilidade aparente (\%) da matéria seca, obtidos nos dois grupos de animais, diária e individualmente durante 10 dias consecutivos, bem como as respectivas médias, erros, desvios e coeficientes de variação, constam da tabela 1 .

Tabela 1 - Coeficientes de digestibilidade aparente (\%) da matéria seca de capim Napier (Pennisetum purpureum Schum) obtidas diariamente em fêmeas taurinas e zebuinas.

\begin{tabular}{lllllllllllllll} 
Dias & 60. & 70 & 80 & 90 & 100 & 110 & 120. & 130 & 140. & 150 & média erro & s & CV\% \\
\hline
\end{tabular}

\section{Lote I - Bos taurus}

Anim.no.

\begin{tabular}{crrrrrrrrrrrrr}
1 & 46,80 & 49,36 & 41,98 & 38,67 & 40,54 & 43,42 & 41,15 & 47,93 & 48,25 & 41,15 & $43,93 \pm 1,21$ & 3,82 & 8,69 \\
2 & 39,42 & 32,37 & 45,11 & 36,48 & 40,02 & 47,25 & 49,82 & 43,17 & 33,33 & 45,72 & $41,27 \pm 1,88$ & 5,94 & 14,39 \\
3 & 35,88 & 30,95 & 47,03 & 32,28 & 50,73 & 38,78 & 29,94 & 55,42 & 37,26 & 40,54 & $39,88 \pm 2,73$ & 2,73 & 21,65 \\
4 & 37,21 & 37,21 & 37,21 & 55,11 & 63,70 & 32,45 & 37,21 & 37,21 & 50,29 & 37,21 & $42,48 \pm 3,23$ & 10,21 & 24,03 \\
5 & 48,69 & 37,85 & 45,76 & 55,45 & 57,47 & 37,85 & 37,85 & 35,00 & 37,85 & 51,05 & $44,48 \pm 2,62$ & 8,28 & 18,62 \\
& & & & & & & & & & & & & \\
4 & & & & & & & \\
média & 41,60 & 37,55 & 43,42 & 43,60 & 50,49 & 39,95 & 39,19 & 43,75 & 41,40 & 43,13 & 42,41 \\
erro & $\pm 2,59$ & $\pm 3,24$ & $\pm 1,76$ & $\pm 4,88$ & $\pm 4,65$ & $\pm 2,52$ & $\pm 3,23$ & $\pm 3,70$ & $\pm 3,32$ & $\pm 2,40$ & $\pm 0,85$ \\
s & 5,79 & 7,25 & 3,94 & 10,91 & 10,39 & 5,64 & 7,21 & 8,27 & 7,43 & 5,36 & 1,89 \\
CV\% & 13,92 & 19,30 & 9,07 & 25,02 & 20,58 & 14,12 & 18,40 & 18,90 & 17,95 & 12,44 & 4,46 \\
\hline
\end{tabular}

\section{Lote II - Bos indicus}

Anim.no.

\begin{tabular}{|c|c|c|c|c|c|c|c|c|c|c|c|c|c|c|}
\hline 6 & 54,40 & 34,61 & 51,85 & 38,62 & 48,87 & 47,91 & 42,53 & 33,54 & 35,25 & 37,72 & $42,53 \pm$ & 2,43 & 7,69 & 18,08 \\
\hline 7 & 54,17 & 42,34 & 53,08 & 37,97 & 59,27 & 41,31 & 40,35 & 34,06 & 44,53 & 43,06 & $45,31 \pm$ & 2,38 & 7,53 & 16,63 \\
\hline 8 & 51,16 & 44,95 & 52,08 & 47,24 & 54,38 & 51,93 & 44,20 & 34,49 & 42,36 & 39,29 & $46,21 \pm$ & 2,01 & 6,37 & 13,79 \\
\hline 9 & 48,05 & 35,09 & 54,10 & 45,66 & 59,36 & 50,22 & 47,76 & 37,80 & 44,22 & 55,34 & $47,76 \pm$ & 2,39 & 7,56 & 15,84 \\
\hline 10 & 50,95 & 39,52 & 63,86 & 46,83 & 51,77 & 42,99 & 48,35 & 48,35 & 60,44 & 49,27 & $50,23 \pm$ & 2,31 & 7,30 & 14,53 \\
\hline
\end{tabular}

\begin{tabular}{lccccccccccccc}
\hline média & 51,75 & 39,30 & 54,99 & 43,26 & 54,73 & 46,87 & 44,64 & 37,65 & 45,36 & 44,94 & 46,41 \\
erro & $\pm 1,17$ & $\pm 2,01$ & $\pm 2,25$ & $\pm 2,05$ & $\pm 2,06$ & $\pm 2,05$ & $\pm 2,05$ & $\pm 1,53$ & $\pm 2,78$ & $\pm 4,13$ & $\pm 3,27$ & $\pm 1,28$ \\
s & 2,62 & 4,50 & 5,04 & 4,58 & 4,62 & 4,58 & 3,41 & 6,21 & 9,23 & 7,32 & 2,86 \\
CV\% & 5,07 & 11,45 & 9,16 & 10,58 & 8,44 & 9,77 & 7,64 & 16,50 & 20,34 & 16,30 & 6,16
\end{tabular}

$\mathrm{s}=$ desvio padrão

$\mathrm{CV}=$ coeficiente de variação

Rev.Fac.Med.vet.Zootec.Univ.S.Paulo, 19(1): 97-100, 1982 
Estudo comparativo da digestibilidade -aparente da matéria seca do capim Napier (Pennisetum purpureum Schum) em bovinos europeus (Bos taurus) e indianos (Bos indicus).

\section{DISCUSSĀO}

Os bovinos europeus (lote I) apresentaram coeficiente de digestibilidade médı de $42,41 \pm 0,85 \%$ (tabela 1 ) e baixa variabilidade entre indivíduos $(4,46 \%)$. As variações ocorridas entre dias para um mesmo animal também não se mostraram muito elevadas, de $8,69 \%$ (animal 1) a $24,03 \%$ (animal 4).

A análise de variância aplicada aos valores individuais diários, não evidenciou diferenças de significância estatística entre os animais deste grupo.

Os de origem indiana (lote II) exibiram coeficiente de digestibilidade médio de $46,41 \pm 1,28 \%$ (tabela 1) e variabilidade, entre eles, ligeiramente maior $(6,16 \%)$ que o encontrado para o grupo europeu $(4,46 \%)$. O coeficiente de variação entre animais concorda com os encontrados por ANDREASI e cols' ${ }^{1}$ para animais da raça Gir.

As variaçōes entre dias, foram mais uniformes, de $13,79 \%$ (animal 8) a 18,08\% (animal 6), entre os zebuinos que os observados no lote I (tabela 1).

Da mesma forma que o sucedido para o grupo constituído de animais europeus, a análise estatística permitiu atribuir ao acaso as diferenças entre zebuinos (lote II).

$\mathrm{O}$ confronto entre os valores diários individuais dos lotes revelou que as diferenças entre eles foram de significância estatística, apesar do animal 6 , da origem indiana, mostrar menor coeficiente de digestibilidade $(42,53 \pm$ $2,43 \%$ ) que os apresentados pelos europeus de números 1 a 5 , quais sejam $43,93 \pm 1,21 \%$ e $44,48 \pm 2,62 \%$, respectivamente.

Os valores médios obtidos no presente estudo para os animais europeus foram semelhantes aos encontrados por VELLOSO e cols 11 em machos mestiços Holandês x Zebú alimentados com capim gordura (Melinis minutiflora) com 180 dias $(41,2 \%)$, inferiores ao encontrado para o capim com 120 dias $(56,5 \%)$ e superiores aos atribuídos para a forrajeira de 60 dias $(31,7 \%)$. O grupo zebuíno, por outro lado, mostrou valores mais elevados que os encontrados por aqueles autores para os capins de 60 a 180 dias, sendo inferiores apenas aos obtidos para o de 120 dias.

Por outro lado, os valores aqui obtidos para os zebuínos confirmam os achados de RAZDAN e cols ${ }^{6}$ (de 49,63 e $46,83 \%$ ) obtidos em fêmeas da raça Tharparkar, com pesos semelhantes aos das fêmeas utilizadas no presente estudo.

Convém assinalar que FONSECA e cols ${ }^{3}$, em tauri. nos, observaram que o consumo de capim Napier decresce com o avançar da idade da gramínea.

$\mathrm{O}$ encontro de diferenças entre Bos taurus e Bos indicus era, até certo ponto, esperado, uma vez que experimentos em outros países 5 já haviam evidenciado a maior capacidade que os zebuinos e seus mestiços possuem para digerir alimentos volumosos, quando confrontados com raças européias, ainda que as comparações tivessem sido efetuadas através de provas "in vitro" (GRANT e cols 4 ).

Portanto, relativamente a esta característica, os Nelores criados no Brasil mostraram comportamento semelhante ao das demais raças de zebuinos existentes em outros países.

Coeficientes de digestibilidade mais elevados para zebuinos parecem indicar condições de rúmen diferentes das encontradas nos bovinos europeus, embora GRANT e cols $^{4}$ julguem que essas diferenças não possam ser explicadas por diferenças entre os fluídos do rúmen.

NOGUEIRA FILHO, J.C.M.; VEIGA, J.S.M.; OLIVEIRA, M.E.M.; ROCHA, U.F.: VEIGA, M.C.M. A comparative study of the apparent digestibility of dry matter of "Napier" grass (Pennisetum purpureum Schum) using taurine and zebuine cattle. Rev.Fac.Med.vet.Zootec.Univ.S.Paudo, 19(1): 97.100, 1982.

SUMMARY: The apparent coefficient of digestibility of "Napier" grass was comparatively studied in 10 heifers ( 5 Bos taurus and 5 Bos indicus) using the daily total collection or the $\mathrm{Cr}_{2} \mathrm{O}_{3}$ indicator method for estimation of both and faecal output. Results show that the zebuine heifers had a better digestibility coefficient than the taurine heifers $(P<0,05)$. These results are in accordance with others observed for other zebuine in other places.

UNITERMS: Food, digestibility*; Bovine*; Bos taurus; Bos indicus

\section{REFERENNCIAS BIBLIOGRĀFICAS}

1- ANDREASI, F.; MASOTTI, N.; VEIGA, J.S.M. Aplicabilidade dos métodos indicadores - óxido crômico e cromogêneos - para a determinação da digestibilidade aparente em zebú (Bos indicus). Rev.Fac.Med.vet.S.Paulo, 6(4):401-33, 1960/62.

2- A.O.A.C. Association of Official Agricultural Chemists. Official methods of analysis. 9.ed. Washington, 1960.
3- FONSECA, J.B.; CAMPOS, J.; CONRAD, J.H. Estudos de digestibilidade de forrageiras tropicais pelo processo convencional. Experientiae, Viçosa, 5(3):43-68, 1965.

4- GRANT, R.J.; VAN SOEST, P.J.; MCDOWELL, R.E. Influence of rumen fluid source and fermentation time on in vitro true dry matter digestibility. J.Dairy Sci., 57:1201-5, 1974. 
5- HUNGATE, R.E.; PHILLIPS, G.D.; HUNGATE, D.P.; MAC GREGOR, A. A comparison of the rumen fermentation in european and zebu cattle. J. agr.Sci., Cambridge, 54:196, 1960.

6- RAZDAN, M.N.; SHARMA, D.D.; BHARGAVA, P.V.; CHAWLA, M.S. Utilization of urea and water metabolism by zebu cattle and buffaloes under tropical condition. J.Dairy Sci., 54:1200-6, 1971.

7- RENDEL, $\mathrm{J}$. The role of breeding and genetics in animal production improvement in the developing countries. Genetics, 78:563-75, 1974.

8- SCHURCH, A.F.; LLOYD, L.E.; CRAMPTON, E.W. The use of chromic oxide as an index for determining the digestibility diet. J.Nutr., $41: 629-36$, 1950.
9- SMITH, A.M.; REID, J.T. Use of chromic oxide as an indicator of fecal output for the purpose of determining the intake of pasture herbage by grazing cows. J.Dairy Sci., 38:515-24, 1955.

10- SNEDECOR, G.W. \& COCHRAN, W.G. Statistical methods. 6.ed. Ames, Iowa State University Press, 1967.

11- VELLOSO, L.; PROCKNOR, M.; STRAZZACAPPA, W.; SEKI, K. Digestibilidade (aparente) e produção torrageira de um pasto de capim gordura (Melinis minutiflora Pal de Beauv) Fase I. Período de verão. Rev.Fac.Med.vet.Zootec.Univ.S. Paulo, 15(1):117-26, 1978.

Recebido para publicação em: 03-03-82. Aprovado para publicação em: 01 -09-82. 